\title{
EXAMINATION OF COOLING SYSTEMS IN MACHINE TOOLS REGARDING SYSTEM STRUCTURE AND CONTROL STRATEGIES
}

\author{
C. Steiert*, Ju. Weber, J. Weber \\ Technical University Dresden, Chair of Fluid- Mechatronic Systems, Dresden, Germany \\ *Corresponding author; e-mail: christoph.steiert@tu-dresden.de
}

\begin{abstract}
When analyzing machine tools it is observable that despite sufficient cooling capacity thermo-elastic deformation of the machine structure is badly compensated due to heat input. The reason is the missing adaption of coolant and heat input into the system structure during the process, resulting in insufficient productivity and quality.

In this paper, various system configurations are shown that can be used to achieve both adequate thermal performance and a reduction in energy consumption.
\end{abstract}

\section{Keywords:}

Machine Tools; Fluid Cooling Systems; Thermal Behavior; Energy Efficiency; Closed Loop Control; Main Spindle; Experiment

\section{INTRODUCTION}

Machine tools are part of many machine parks. They are indispensable especially for cutting, drilling, and grinding processes. In recent years, the requested quality and accuracy of work pieces as well as the demanded productivity of machine tools has risen. Increased productivity leads to higher power consumption that is converted into heat. The heat dissipates into the machine structure. The resulting temperature field varies in time and location. Due to an inhomogeneous temperature field and the used materials, one can observe an elastic deformation and at the end occurs a displacement of the Tool Center Point (TCP). The TCP-displacement has a negative influence on the accuracy and quality of the produced work pieces. [Mayr 2012] claims that $75 \%$ of all geometric errors of machined workpieces can be traced to temperature variations of the machine. The described process flow is known as thermo-elastic chain.

Heat sources with a great impact on the machine tool are main spindles, bearings auxiliary units, and the cutting process. To prevent machine tools from thermo-elastic deformation, heat flow inside of the machine tool has to be controlled. A method for controlling heat flow is the installation of fluid cooling systems. Such systems can absorb heat near the source and transport it to the environment where it dissipates. When observing the power consumption of the machine tool one can see that the cooling and lubricant system take about $45 \%$ of the overall power [Brecher 2012; Denkena 2013; Shabi 2020].

\section{STATE OF THE ART}

Fluidic cooling and lubricant systems are main components of today's machine tools. They are used to receive a desired temperature in the machine tool and help preserve the thermo-elastic state of it. Manufactures of machine tools install a high amount of cooling capacity but it is not adapted to the spatial and temporal variation of heat flow through the process, auxiliary units or environmental influences. In conventional machine tools without energy saving mode the cooling system works with constant settings. The projects "NCplus" [Denkena 2013], "EWOTeK" [Brecher 2012] and "Maxime" [Abele 2013] reduce the energy consumption of machine tools with an optimization of the auxiliary units through an adaption of control strategies and adaptable drives. An example with a high potential is the automatic shutdown of unneeded system parts during idle times or the use of variable drive units e. g. fans, pumps or electric drives. Heavy cutting is addressed in the project "Leanergie" [Denkena 2015]. The aim was to implement an "energy navigator" that computes energy consumption during the engineering process and enables the calculation of resulting costs. An "eco-mode" was developed that adapts the cutting parameters during the process. For a better understanding of the energetic behaviour of machine tools the project eSimPro [Abele 2012] implemented a software tool to simulate the energy demand of machine tools including auxiliary units. Two aspects were in the scope, first the support during the development process of machine tools and second the simulation of one tooling task. Both aspects should show optimization potential to save energy. [Li 2019] investigated the structural cooling 


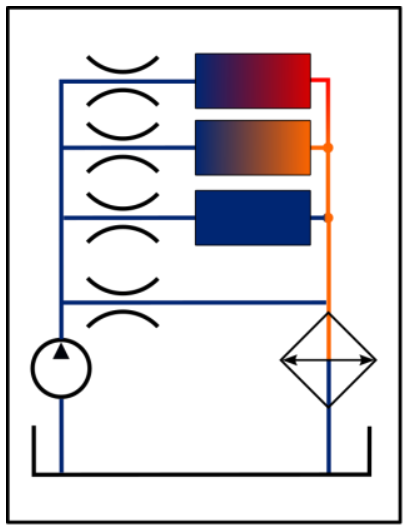

conventional structure

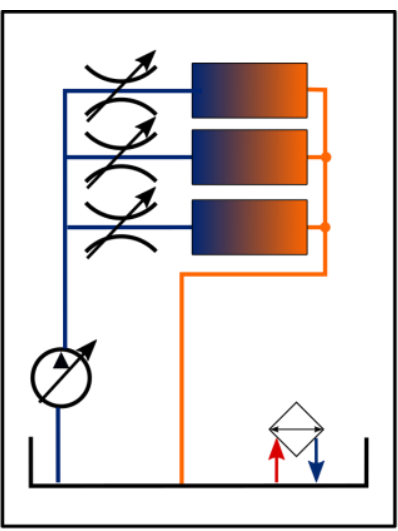

cooling structure 1

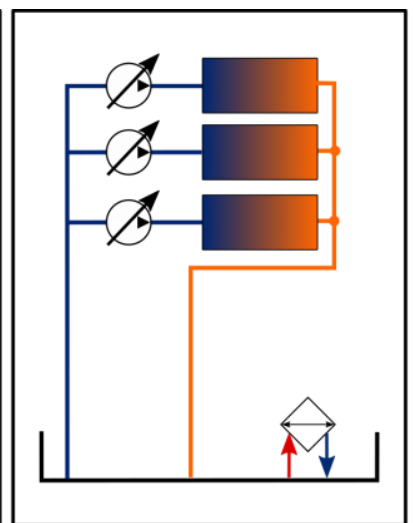

cooling structure 2

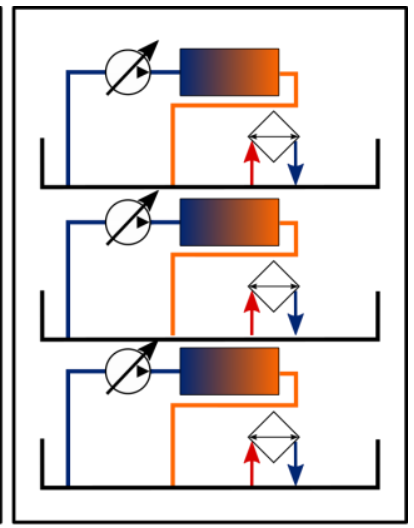

cooling structure 3

Fig. 1: System structures [Shabi 2020]

effect in a hydrostatic guideway on the position accuracy in a machine tool with respect to the coolant temperature. Here the inlet temperature is controlled with constant volume flow. [Mares 2020] show the effects cooling systems have on thermal error models and compensation methods. All above mentioned projects have the reduction of energy consumption with optimization of auxiliary units or load adapted control strategies in common. The concepts discussed in this paper are the investigation of new structures where aspects like load adapted control strategies play a major roll.

\section{SYSTEM DESCRIPTION}

\subsection{Cooling System structures with decentralized coolant supply}

Research activities like [Brecher 2012; Denkena 2013] gained energy savings by optimizing separate aggregates or implementing a switched control strategy, where subsystems are switched of when they are not needed. The proposed strategy of [Shabi 2020] is different. Here, a decentralized supply with coolant is the proposed method, especially for a constant temperature field in machine tool structures.

A way to calculate heat transfer from the machine tool to the coolant is Fourier's law:

$$
\dot{Q}=\alpha \cdot A \cdot\left(\vartheta_{M T}-\vartheta_{\text {Fluid }}\right) \text {. }
$$

$\dot{Q}$ is the heat flow transferred from the machine tool to the fluid, $\alpha$ is the heat transfer coefficient, $A$ is the contact area between machine tool and fluid and $\vartheta_{\mathrm{MT}}-\vartheta_{\text {Fluid }}$ is the temperature difference between machine tool and fluid. Assuming that the machine tool temperature $\vartheta_{\mathrm{MT}}$ is constant, there are two variable parameters. The fluid temperature $\vartheta_{\text {Fluid }}$ and the heat transfer coefficient with the following functional convergence:

$$
\alpha=\frac{\lambda}{L} \cdot N u(\operatorname{Re}, \operatorname{Pr}) .
$$

In this context $\lambda$ is the heat conductivity of the fluid, $L$ is the characteristic length and $N u$ is the Nusselt number, a dimensionless ratio depending from Reynolds number $R e$ and the Prandl number $\mathrm{Pr}$. With $\mathrm{Pr}$ depending from fluid properties and $R e$ having dependencies from flow velocity the heat transfer coefficient $\alpha$ varies with the flow velocity, through the cooling pipe and therefore with the volume flow. To vary the heat flow over time, only volume flow and fluid temperature are available as control elements. Fig. 1 shows two possibilities for controlling the volume flow. In cooling

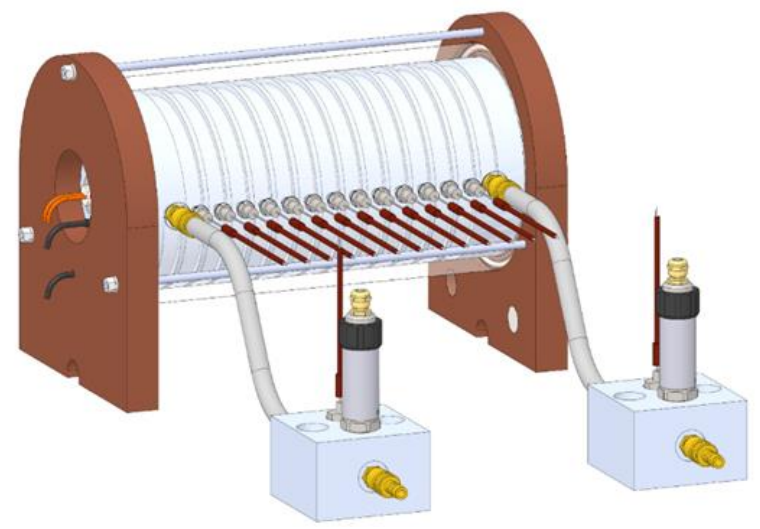

Fig. 2 Cooling sleeve
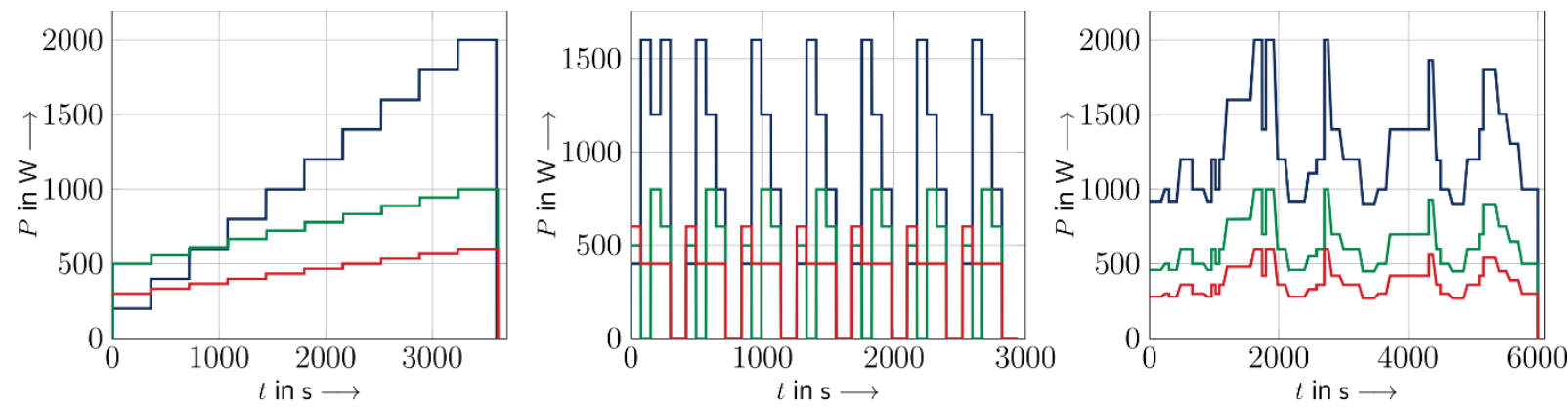

Cooling circuit $1-$ Cooling circuit $2-$ Cooling circuit 3

Fig. 3 Load cycles [Shabi 2020] 
structure 1 proportional valves are used to deliver the right amount of volume flow and in cooling structure 2 and cooling structure 3 the main focus is on variable speed drive pumps. In addition, cooling structure 3 features complete separate circuits with a tank, a pump, and a heat exchanger for each component, whereas in cooling structure 2 the tank and heat exchanger for re-cooling are used for all three cooling circuits. Therefore, the inlet temperature for the three cooling circuits is controllable for each subsystem separately in cooling structure 3 .

\subsection{Test rig to perform different cooling structures}

The three cooling structures from Fig. 1 can be experimentally analysed with a test rig. The main components of this test rig are three speed variable drive pumps and proportional valves for controlling the volume flow. Switching valves are installed to operate the various cooling structures. The re-cooling of the fluid is done through a water-water heat exchanger that receives the coolant from a central cooling supply. With this system the fluid temperature in the tank can be kept constant for each experiment. To emulate the heat sources three instantaneous water heaters are installed. Two with a maximum power of $1500 \mathrm{~W}$ and the third is a cooling sleeve for a main spindle described in section 3.4. A more detailed description of the construction of the test rig can be found in [Shabi 2019].

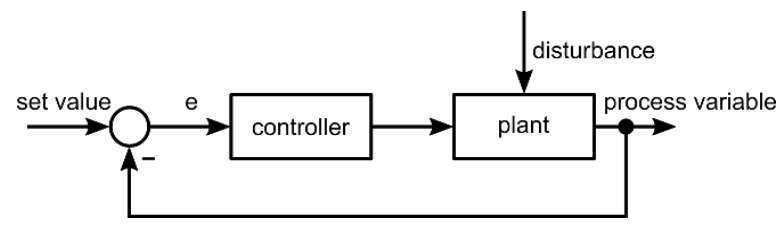

Fig. 4 Control system

\subsection{Control concept}

The control concept is based on a standard single-input single output system. The three cooling circuits installed on the test rig can be regarded as independent. They share parts like the tank or actuators but for the control concept, this is not taken into account, because the cooling capacity of the tank is large enough. Therefore, no disturbance regarding the cooling properties is to be expected. Each circuit gets its one control loop that is shown in Fig. 4. The set values for the experiments are set to $25.0^{\circ} \mathrm{C}$ for the first circuit with the cooling sleeve installed. The second circuit has a set value of $24.0^{\circ} \mathrm{C}$ and the third one is set to $23.0^{\circ} \mathrm{C}$. Depending on the cooling structure the variable speed drive pumps or the control valves are controlled with a PIcontroller. The set values for the controllers are accessed experimentally. The plant is the fluid system e. g. seen in Fig. 1. The disturbance the controller reacts to is the instantaneous heat exchanger. When more heat is introduced into the system, more coolant is delivered from the actuators. This concept shows sufficient accuracy during experiments. When examining structures that are more complex where the heat flow inside of the machine tool cannot be separated, the control concept has to be adapted to multi-input multi-output systems. This will be the case for a machine tool. The experiments shown in paragraph 4 are designed to keep the fluid temperature constant at the outlet due to the experimental design. In a machine tool temperature sensors are needed to gain thermal information of the machine tool structure as a process variable. By controlling the temperature of the machine tool frame the displacement of the TCP can be reduced. This circumstance requires extended control concepts, such as cascaded control loops with a slow

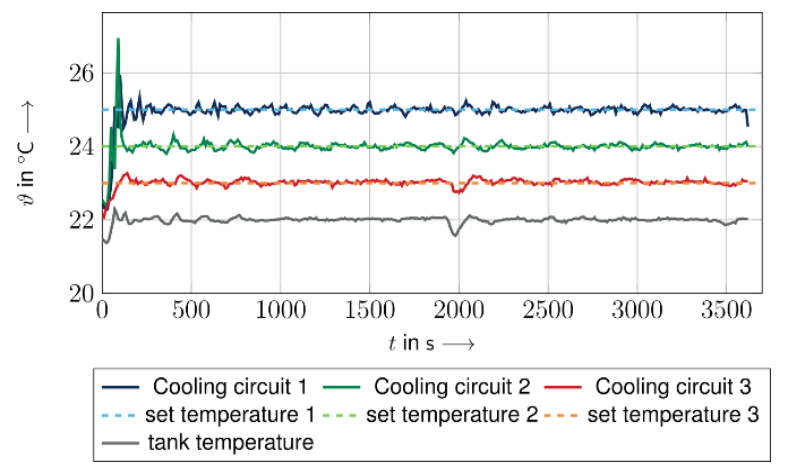

Fig. 5 Cooling structure 1 with load cycle 1

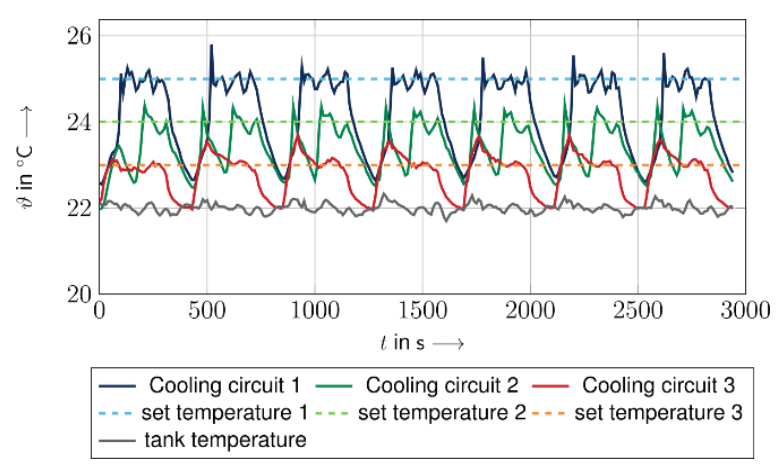

Fig. 6 Cooling structure 1 with load cycle 2

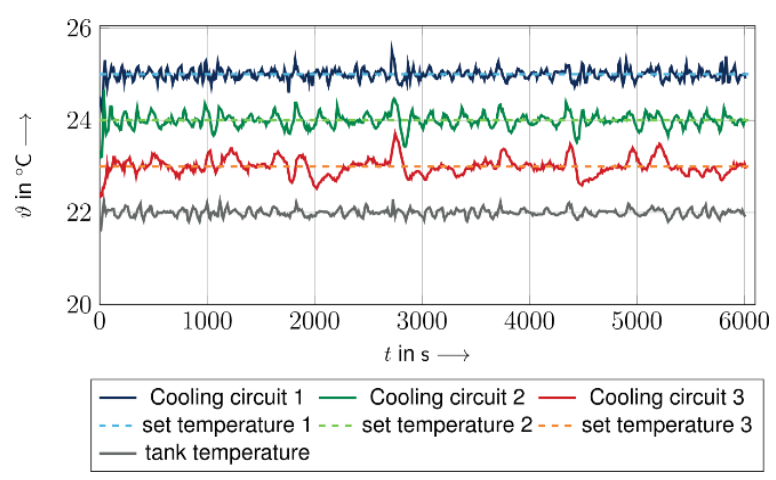

Fig. 7 Cooling structure 1 with load cycle 3

temperature control loop and a fast control loop for volume flow control for machine tools.

\subsection{Cooling sleeve for main spindles}

The cooling sleeve used in the test rig, represents the thermal and fluidic properties of one used in machine tools. In Fig. 2 the mechanical design is shown with the different components labelled. The central element is the cooling sleeve a cylindrical aluminium body with a helical groove where the coolant flows through. Around the sleeve is an acrylic glass pipe which fits exactly the outer diameter of the sleeve. It seals the grooves at the bar and the fluid can only stream along the desired path without leakage between the separated turns. On both edges of the cooling sleeve thermo-isolating plates are installed to prevent heat transfer to the environment. In addition, a housing from acryl glass is around the whole cooling sleeve and sensors to prevent convection. The cooling sleeve is equipped with temperature sensors at the in- and the outlet and one sensor at each turn. With these sensors the temperature profile of the cooling sleeve can be measured. Additionally, two pressure sensors are integrated to measure the pressure loss over the cooling sleeve. The inside of the 
aluminium body is filled with two heaters, each can be controlled separately and delivers from $0-1400 \mathrm{~W}$ each. It is possible to set constant load or run variable load profiles. These heaters emulate the heat coming from the electromotor of the main spindle. The integration of the cooling sleeve in the test system test rig is a further step to adapt the concept to a real machine tool. A more detailed view on design and investigation on cooling sleeves can be found in [Weber 2018].

\section{EXPERIMENTAL RESULTS}

In order to test the cooling structures with regard to temperature stability and energy consumption of the hydraulic pumps that supply the coolant to the different channels, three load cycles are applied. The load cycles are on different power levels for each circuit. The circuit with the cooling sleeve has the highest level and the two other circuits are on lower levels. The three load cycles are represented in Fig. 3. In load cycle 1 the heat flow increases in a quasi-static manner. This should show the potential to cope with different static loads. The second load cycle shows the power input through the production with different tools. This leads to time periods where no load is applied and the machine structure is cooled down. The last investigated load cycle is created with input from industrial partners. It contains load peaks, negative ramps and stationary states. The results shown in the following graphs show the outlet temperature at the corresponding cooling circuit. These temperatures are the process variables for the controller. The set values are $25.0^{\circ} \mathrm{C}, 24.0^{\circ} \mathrm{C}$ and $23.0^{\circ} \mathrm{C}$ for cooling circuit 1 , cooling circuit 2 and cooling circuit 3 in all cooling structures and for each load cycle. A minimum volume flow of $2 \mathrm{l} / \mathrm{min}$ flows through each cooling circuit to detect temperature changes.

\subsection{Cooling structure 1}

The first cooling structure controls the volume flow with a combination of valves and speed variable drives. The pump control is responsible for delivering the right amount of volume flow and the valves control the distribution to the three circuits. The circuit demanding the highest amount of volume flow has a completely opened valve to minimiz the energy consumption. The opening degree of the two other valves depends on the volume flow needed. In general, it is possible to swap the completely opened valve from circuit to circuit but the valves have to be fast enough to follow the control signal. This behavior can be simulated. At the test rig it was not possible to implement such a behavior because for one strike of the valve $30 \mathrm{~s}$ are necessary and that is not sufficient for this control concept. The results for load cycle 1 can be found in Fig. 5. At the beginning of the load cycle the temperature rises and an overshoot occurs for cooling channel 1 and cooling channel 2 . The valves start opening when the set temperature is reached and it needs some time until the corresponding volume flow is reached. For cooling channel 3 this is not the case, because here the corresponding valve is totally open and the volume flow is set with the drive speed of the pump which adjusts faster. Despite the load steps the temperature control can set the right amount of volume flow. The resulting temperatures vary around the set temperature of less than $0.4 \mathrm{~K}$ in a small band. The results for the second load cycle are plotted in Fig. 6. The set temperature for the different cooling circuits is reached for periods. In between these periods the temperature declines, because no heat is introduced in the system, but the minimal volume flow is applied. The third load cycle is shown in Fig. 7. In this load cycle a certain load is applied for the whole time which is why no strong temperature

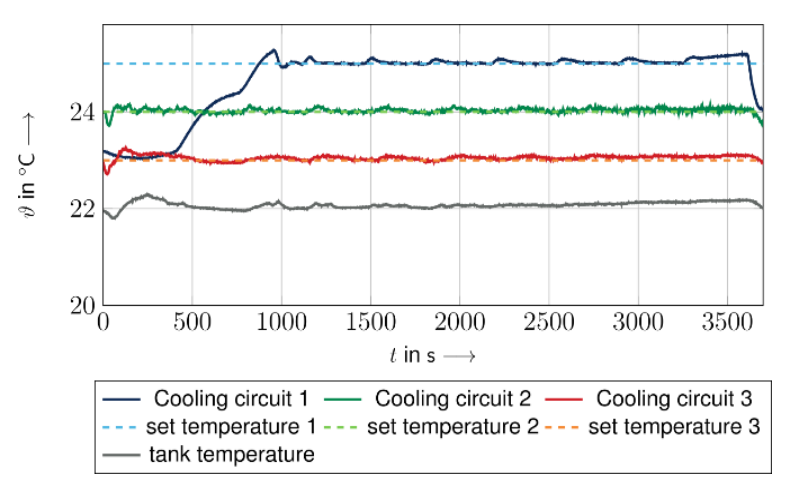

Fig. 8 Cooling structure 2 with load cycle 1

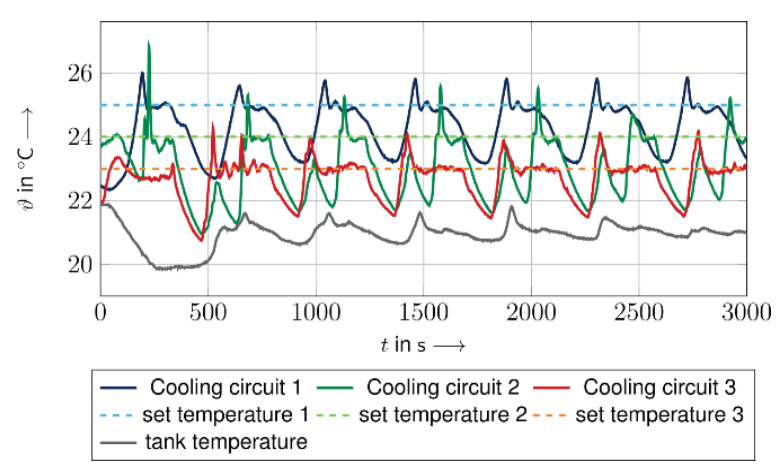

Fig. 9 Cooling structure 2 with load cycle 2

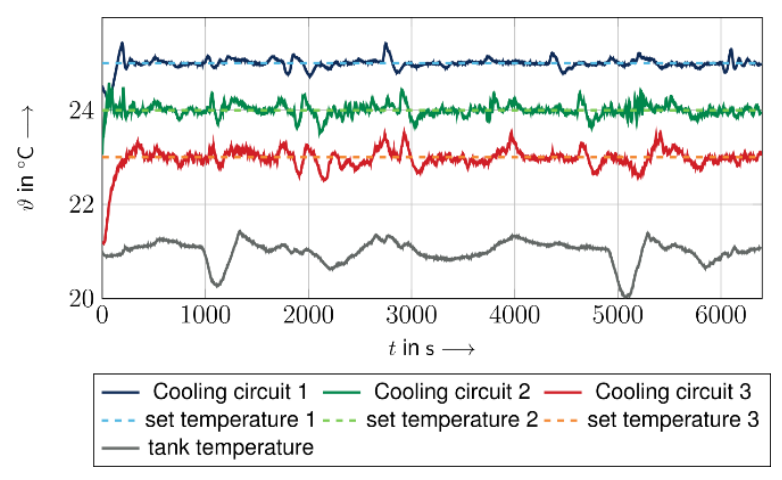

Fig. 10 Cooling structure 2 with load cycle 3

drops are seen in this diagram. The temperature variation in slightly larger in comparison to load cycle 1 with a temperature band of $0.8 \mathrm{~K}$.

\subsection{Cooling structure 2}

The control elements in cooling structure 2 are speed variable drive pumps - one for each cooling circuit. With them a good temperature control is possible. In Fig. 8 the result for the first load cycle is printed. At the beginning, the fluid is heated through the process. When the set value for the temperature is reached only derivations in a range of $0.2 \mathrm{~K}$ occur. When looking at Fig. 9 the second load cycle is applied to cooling structure 2. Here the situation is different. There are load steps from $0 \mathrm{~W}$ to the maximum load varying from $600 \mathrm{~W}$ to $1600 \mathrm{~W}$. These big steps result in an overshoot of the temperature. Depending on the properties of the controller the dynamic behavior can be handled in different manners. In this situation the decision is to minimize the first undershoot. The overshoot is in a range of $1.0 \mathrm{~K}$ to $1.5 \mathrm{~K}$. Afterwards the temperature oscillates around the set temperature with a small amplitude. When no heating power is applied to the cooling sleeve or the instantaneous water heaters the temperature 
drops down near the inlet temperature of the coolant. To detect temperature changes with little time delay a volume flow of $2 \mathrm{l} / \mathrm{min}$ in every circuit is necessary. This volume flow is enough to cool the heaters under the set temperature. A solution to avoid this problem is the measurement of the structure temperature e.g. main spindle temperature instead of the fluid temperature. In the test rig only temperature sensors for measurement fluid temperatures are integrated. The last load cycle investigated in the scope of this paper is load cycle 3 where the results are plotted in Fig. 10. After a short heating phase, where the fluid reaches the set temperature for each cycle, the temperature remains constant for almost two hours even though load cycle 3 is very dynamic.

In all three load scenarios the set temperature is fulfilled. Comparing this behavior with an uncontrolled system often used in the industry, a better temperature stability is obvious. As an example Fig. 14 shows the temperature plot for the conventional system structure. The temperature follows the power input of the three heaters. The volume flow is set to $5.5 \mathrm{l} / \mathrm{min}$ for the circuit with the cooling sleeve, $4.5 \mathrm{l} / \mathrm{min}$ for the second circuit and $2.9 \mathrm{l} / \mathrm{min}$ for the third circuit. The energy consumption of all three pumps for load cycle 3 measured at the conventional system structure is by $243 \mathrm{Wh}$ and for system structure 2 the energy is $183 \mathrm{Wh}$. This is an energy reduction of $25 \%$ for the pumps.

\subsection{Cooling Structure 3}

Cooling structure 3 is a more decentralized structure than cooling structure 2. Each circuit has his own tank and therefore the inlet temperature can be adjusted independently in each circuit. Because only one tank is available on the test rig, the different circuits are investigated consecutively. All three circuits are independent from each other and there are no cross connections. With this in mind only the circuit with the cooling sleeve installed will be investigated. The temperature behavior for all three load cycles is shown in Fig. 11, Fig. 12 and Fig. 13. Additionally, to the outlet temperature, and the set temperature the volume flow are plotted. It can be observed from the volume flow behavior that the pumps deliver a more or less proportional volume flow as the heat flow introduced into the system (compare Fig. 3). For load cycle 1 the volume flow is constant for the first $1000 \mathrm{~s}$, this is because here the set temperature of $25.0^{\circ} \mathrm{C}$ is not reached, but the minimum volume flow has to be delivered. After reaching the set temperature the volume flow rises stepwise due to the additional heat input. A detail to mention here is the slightly greater temperature ripples in comparison to cooling structure 2 (see Fig. 8). The reason for this can be found in a firmly adjusted controller and the temperature oscillation of the inlet temperature (varying between $21.0 \mathrm{C}$ and $22.5 \mathrm{C}$, cycle time $50-100 \mathrm{~s}$ ) that leads to a stable oscillation of the temperature. These temperature ripples can be found as well in the measurement of load cycle 3 (see Fig. 13). No advantages between the two structures can be observed regarding the temperature stability.

\subsection{Temperature control with feed forward}

A method to improve the temperature behavior when the temperature is more stable is an extension through a feed forward control. In this case the heat input from the process is necessary. For large scale productions where one machine tool does the same job all the time, it is possible to measure the heat input. With the measured heat input, set temperature and inlet temperature the necessary volume flow can be calculated through equation $\dot{Q}=\alpha \cdot A \cdot\left(\vartheta_{M T}\right.$

$\begin{array}{ll}\left.\vartheta_{\text {Fluid }}\right) . & (1) . \dot{Q}=\alpha \cdot A \cdot\left(\vartheta_{M T}-\right. \\ \left.\vartheta_{\text {Fluid }}\right) . & \text { (1With the aid of }\end{array}$

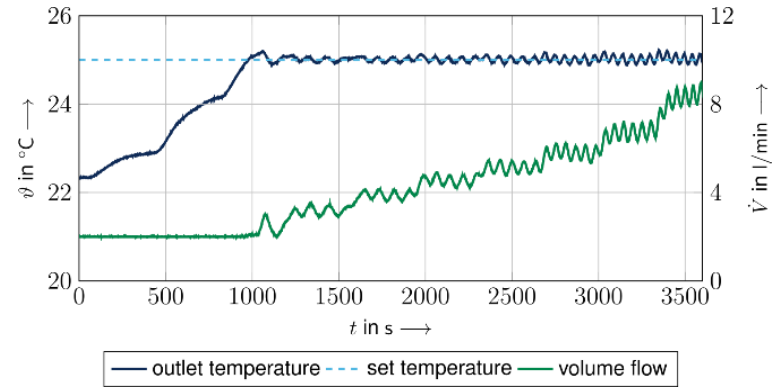

Fig. 12 Cooling structure 3 with load cycle 1

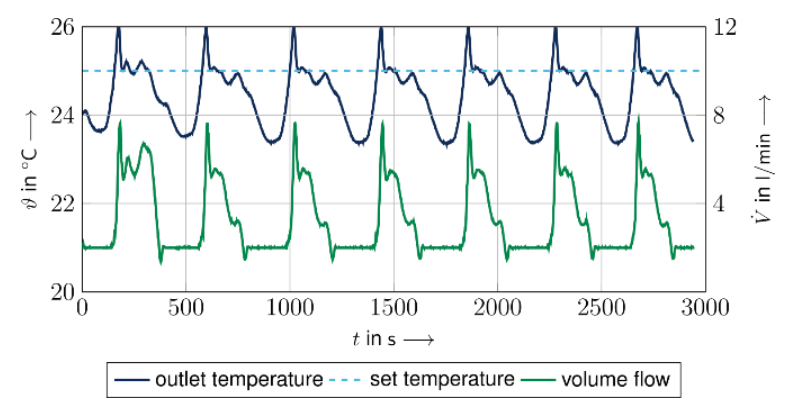

Fig. 13 Cooling structure 3 with load cycle 2

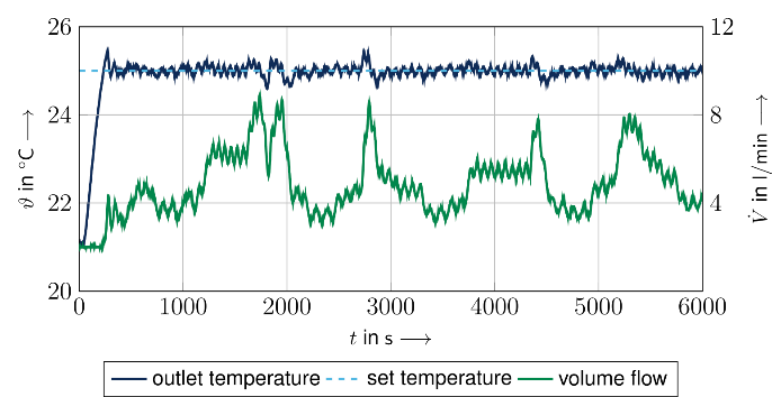

Fig. 14 Cooling structure 3 with load cycle 3

characteristic diagrams the volume flow can be transformed to input voltages for the pumps. Initial experiments show advantages when high load steps are performed. Running the experiment with cooling structure 2, load cycle 2 and an additional feed forward control the temperature peaks can be reduced to $0.5 \mathrm{~K}$. Without the feed forward path the peaks were between $1 \mathrm{~K}$ and $1.5 \mathrm{~K}$ (compare Fig. 9). With feedforward control it is also possible to reduce maximum loads e.g. for the pump delivering the volume flow. When starting earlier to increase the volume flow, because the knowledge of the coming load step is available, the maximum volume flow is reduced and less peak load is

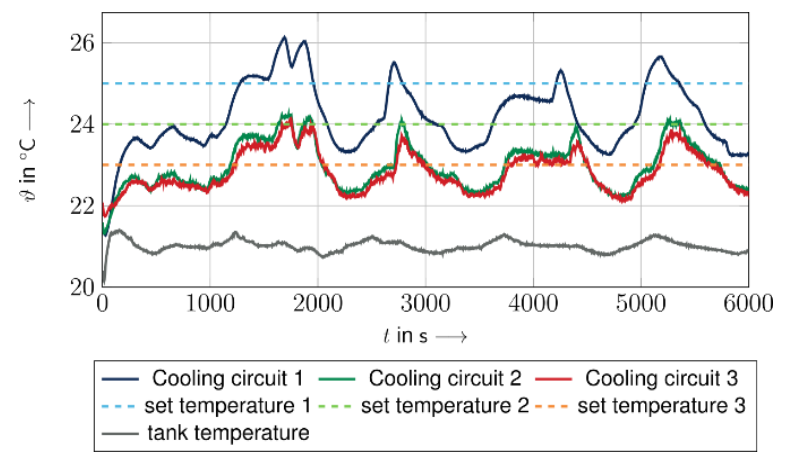

Fig. 11 Load cycle 3 without temperature control 
demanded from the pump. This results in a longer life time of the used parts and therefore service costs are reduced as well. Another advantage of the feed forward control lies in the opposite case, when a negative load step is performed. The feedforward path can adjust the volume flow by reducing it earlier and consequently the temperature is not decreased as much as without the feedforward control. For the presented load cycle this is especially the case for load cycle 2 the case, where the heat input is $0 \mathrm{~W}$ between the different steps. If the gap between two heat input phases is too large the temperature drop is only delayed.

\section{OUTLOOK AND CONCLUSION}

This paper describes a new structural approach for cooling systems in machine tools. Based on the state of the art and energy measurements at machine tools, new cooling strategies were derived and executed on test rigs. The results show a thermal stability with temperature derivations of less than $0.5 \mathrm{~K}$ and a reduction of energy consumption of the cooling system by $25 \%$.

The next steps to approach a full integration of the desired cooling system structure in a machine tool are:

- Integration of a cooling structure that enables a variable volume flow, into a demonstrator machine tool, where the main spindle is cooled

- Examination of the cooling strategies on a DMU 80 with thirteen separate cooling channels.

- Determination of the thermo-elastic deformation with optimized cooling strategies

- Derivation of a concept for energy optimized cooling systems and control strategies

These further experiments aim to show the applicability of the concept with little economical effort and advantages for productivity and energy efficiency.

\section{ACKNOWLEDGMENTS}

The presented research activities are part of the project A04 "Thermo-energetic description of fluid systems" founded by the German Research Foundation (Project-ID 174223256 TRR 96). The authors would like to thank the German Research Foundation (DFG) for the financial support.

Funded by

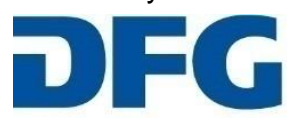

\section{Deutsche} Forschungsgemeinschaft

\section{REFERENCES}

\section{Paper in a journal:}

[Shabi 2019] Shabi, L. et al. Entwicklung eines Versuchsstands zur Untersuchung alternativer Kühlsystemstrukturen und -betriebsstrategien von
Werkzeugmaschinen, Antriebstechnik, 58[9], pp. 98-107, 2019.

\section{Paper in proceedings:}

[Weber 2018] Weber, J. et al. State of the art and optimization of the energy flow in cooling systems of motorized high-speed spindles in machine tools. Procedia CIRP. 11th CIRP Conference on Intelligent Computatuin in Manufacturing Engineering, pp. 81-86, 2018.

\section{Technical reports or thesis:}

[Abele 2012] Abele, E. et al. Energieeffiziente Produktionsmaschinen durch Simulation in der Produktentwicklung - Ergebnisbericht des BMBF Verbundprojekts eSimPro. Darmstadt: PTW TU Darmstadt, 2012.

[Abele 2013] Abele, E. et al. Schlussbericht zum Projekt Maxiem - Maximierung der Energieeffizienz spanender Werkzeugmaschinen. Darmstadt, 2013.

[Brecher 2012] Brecher, C. et al. Effizienzsteigerung von Werkzeugmaschinen durch Optimierung der Technologien zum Komponentenbetrieb - EWOTeK. 1st edn. Aachen: Apprimus Verlag, 2012.

[Denkena 2013] Denkena, B. NCplus - Prozess- und Wertschöpfungsorientiert gesteuerte Werkzeugmaschine. PZH-Verlag - Garbsen: TEWISS - Technik- und Wissen$\mathrm{GmbH}, 2013$

[Denkena 2015] Denkena, B. et al. LEANERGIE Lebenszyklusorientierte Lösungen und Dienstleistungen für Gestaltung und Betrieb energieeffizienter Werkzeugmaschinen. Hannover: Institut für Fertigungstechnik und Werkzeugmaschinen, Leibniz Universität Hannover, 2015.

[Li 2013] Li, K.-Y. et al. 'Effect of supply cooling oil temperature in structural cooling channels on the positioning accuracy of machine tools', Journal of Mechanics, 35[6], pp. 887-900, 2019.

[Mares 2020] Mares, M. et al. 'Effects of cooling systems on the thermal behaviour of machine tools and thermal error models', Journal of Mechanical Engineering, 20[4], pp. 527, 2020.

[Mayr 2012] Mayr, J. et al. 'Thermal issues in machine tools', CIRP Annals, 61(2), pp. 771-791, 2012.

[Shabi 2019] Shabi, L. et al. 'Entwicklung eines Versuchsstands zur Untersuchung alternativer Kühlsystemstrukturen und -betriebsstrategien von Werkzeugmaschinen', Antriebstechnik, 58(9), pp. 98-107, 2019.

[Shabi 2020] Shabi, L. Themo-energetisch optimierte FluidSysteme für Werkzeugmaschinen. Dissertation. Technische Universität Dresden, 2020.

[Weber 2018] Weber J. et al. 'State of the art and optimization of the energy flow in cooling systems of motorized high-speed spindles in machine tools', in Procedia CIRP. 11th CIRP Conference on Intelligent Computatuin in Manufacturing Engineering, pp. 81-86, 2018. 